\title{
Proposta de modelo para avaliação sistêmica do desempenho competitivo de arranjos produtivos: o caso do arranjo coureiro- calçadista do Vale dos Sinos (RS - Brasil)
}

\author{
Peter Bent Hansen \\ Pontifícia Universidade Católica do RS - PUCRS \\ peter.hansen@pucrs.br \\ Leonardo Rocha de Oliveira \\ Pontifícia Universidade Católica do RS - PUCRS \\ leorocha@pucrs.br
}

Resultados da gestão das empresas e sua competitividade no mercado em que atuam têm se mostrado cada vez mais dependentes do desempenho dos arranjos produtivos onde as empresas se inserem. Este cenário leva à necessidade de desenvolver modelos sistêmicos para avaliação de desempenho que contemplem a competitividade dos arranjos produtivos como um todo. Este artigo discute este assunto e, com base na revisão de literatura, propõe um modelo para avaliação sistêmica do desempenho competitivo de arranjos produtivos. Uma pesquisa exploratória e qualitativa foi desenvolvida com estudo de caso único no setor coureiro-calçadista do Vale dos Sinos. Profissionais de empresas e instituições regulatórias do setor foram entrevistados para analisar a aplicabilidade do instrumento. Resultados da aplicação do modelo apresentam um mapa com forças e fraquezas do setor. As conclusões do trabalham indicam que a versão final do modelo pode também ser usado para análise de desempenho em diferentes arranjos produtivos.

Palavras-chave: arranjos produtivos, competitividade sistêmica, medição de desempenho

Enterprise managerial results and market competitiveness are increasingly dependent on the cluster's performance which the company works with. This scenario drives the need for evaluating performance through systemic models that should be capable of considering the cluster's competitiveness as a whole. This article discusses clusters' systemic competitiveness and, based on a literature review, it presents a model for evaluating clusters' competitive performance. A qualitative and exploratory research was carried out through a case study, interviewing professionals from companies and regulatory institutions of the Vale dos Sinos footwear manufacturing cluster. The model was firstly applied to field experts and results taken from its application show that it provides a map indicating clusters' strengths and weaknesses. It also shows indications that it could be applied for different clusters.

Keywords: productive arrangements, systemic competitiveness, performance measurement.

\section{Introdução}

O acirramento da competição entre empresas e a crescente busca por melhorias de desempenho têm produzido mudanças nas diversas atividades de negócios. Estas mudanças têm se refletido na gestão empresarial e nas relações de negócios, com impacto nos planos estratégicos que atingem empresas e instituições nacionais e internacionais de incentivo ao desenvolvimento econômico.

A contínua evolução da informatização de base microeletrônica, associada ao estabelecimento de parcerias comerciais, têm conduzido a novas formas de arranjos pro- dutivos, muitas vezes levando a uma verdadeira desfronteirização das empresas envolvidas nas relações de negócios.

Para a gestão desses arranjos produtivos e análise de sua competitividade, torna-se necessária a avaliação de desempenho do arranjo como um todo. A revisão de literatura sobre modelos de avaliação de desempenho deste tipo mostra que os atuais modelos ainda carecem de desenvolvimento, na medida em que o foco está na avaliação de uma ou mais empresas individuais (microanálise típica da ciência da administração), ou orientados para a análi- 
se de segmentos econômicos como um todo (macroanálise típica da ciência da economia).

Este trabalho apresenta uma abordagem mesoanalítica cujo foco central é o conjunto das relações entre as empresas (interempresariais) e seus efeitos sobre a competitividade, tanto das empresas individuais, como do arranjo de empresas como um todo. Este contexto de análise também é viven-ciado pelo arranjo produtivo coureirocalçadista do Vale dos Sinos, no RS, Brasil, cuja análise deveria contemplar resultados do relacionamento entre as diversas empresas do arranjo. Até o momento, as análises de competitividade têm sido voltadas a elos ou tipos específicos de empresas (processos de transformação), sem uma visão sistêmica do arranjo.

Nas próximas seções, o trabalho revisa os diferentes tipos de arranjos produtivos e discute a problemática da formulação de estratégias e da avaliação da competitividade em arranjos produtivos. Apresentam-se, também, alguns modelos de avaliação de desempenho de arranjos produtivos, visando a estruturar uma proposta mesoanalítica de avaliação sistêmica de desempenho competitivo nesse tipo de ambiente. A seguir, são apresentadas as considerações metodológicas do estudo. Um modelo para avaliação sistêmica do desempenho de arranjos produtivos é proposto na sequência, fazendo-se, por fim, uma aplicação experimental do mesmo no arranjo coureiro-calçadista do Vale dos Sinos (RS), e apresentandose as considerações finais e implicações do tema abordado.

\section{Arranjos Produtivos e suas características}

Dentre os diversos tipos de arranjos produtivos abordados na literatura, neste artigo serão discutidas as quatro tipificações mais difundidas ao longo das últimas décadas, ou seja: 1. Filière, 2. Clusters, 3. Supply Chain e 4. Redes de Pequenas e Médias Empresas.

\subsection{Filière}

Esta abordagem desenvolvida para avaliar as relações entre empresas foi inicialmente apresentada na década de 60, na França, com foco na análise dos contratos de produção e integração vertical dos negócios agrícolas dos produtores franceses. A mesma foi empregada nos estudos de planejamento e desenvolvimento econômicos da França no final da década de 70 e início da de 80, na qual o modelo foi utilizado para analisar a capacidade da indústria de expandir a cadeia de valor. O termo Filière tem origem no conceito de fio (linha) que une todas as etapas do processo de transformação, desde as matériasprimas até o produto final entregue ao mercado consumidor.
Uma Filière é composta pela sucessão de etapas tecnológicas de produção distintas e separáveis, associadas à utilização de um dado recurso ou produto (RAIKES, JENSEN; PONTE, 2000). Conceitualmente, a Filière toma o aspecto de um subsistema produtivo global, considerando as regras de negócios, restrições governamentais, a malha de relações entre empresas e lógicas de negociação (PEDROSO e HANSEN, 2001).

Para Kliemann e Hansen (2003), a ideia de Filière não apresenta uma limitação de foco para sua aplicação, uma vez que pode possuir diferentes enfoques, de acordo com o objetivo específico de análise. Conforme os mesmos autores, as análises dentro do enfoque de Filière permitem abordagens diversas, entre as quais destacam-se: análise de arranjos produtivos como suporte à formulação de políticas públicas e privadas; análise de arranjos como apoio à avaliação das estratégias empresariais e de inovações no âmbito tecnológico.

Para analisar a estrutura de uma Filière, utiliza-se o procedimento de jusante à montante, ou seja, do fim para o início (BATALHA, 1997). Parte-se das condicionantes impostas pelo mercado consumidor final, principal indutor do comportamento do subsistema, para analisar a Filière a partir de determinado produto ou serviço final até o primeiro elo da cadeia de empresas participantes, etapa por etapa.

Análises segundo o modelo de Filière oferecem resultados que podem ser incluídos na abordagem mesoanalítica proposta neste trabalho. No entanto, este modelo não contempla a medição de desempenho, mas apenas a estruturação das relações de transformação da cadeia. Exemplos de aplicação deste modelo podem ser encontrados em Pires (2001) e Kliemann (1985), os quais discutem características da Filière no segmento moveleiro (fabricação de móveis), e em Batalha (1997), considerando diversas Filières do segmento de agronegócios.

\subsection{Clusters}

Este conceito foi inicialmente apresentado em Porter (1997) e considera os Clusters (arranjos produtivos) como aglomerados geográficos regionais de empresas de determinado setor produtivo. Neste tipo de arranjo, cada tipo de empresa (elo) executa uma atividade cada vez mais especializada do produto ou serviço final do arranjo. Assim, podem existir diversas empresas confeccionando partes ou componentes de um produto acabado, concorrendo entre si e, muitas vezes, também colaborando em determinadas atividades.

Partindo desta definição de caráter geral, Chorincas, Marques e Ribeiro (2001, p. 3) distinguem alguns tipos de Clusters, conforme a seguir: 
- Cluster Industrial: conjunto de empresas inter-relacionadas, tais como fornecedores especializados, prestadores de serviços, indústrias vinculadas e instituições diversas (desde Universidades até centros de certificação de qualidade e associações comerciais) que desenvolvem atividades diferentes, mas todas relacionadas à atividade principal, recorrendo a tecnologias distintas e/ou complementares que, pela inovação que geram, concretizam benefícios para as demais, sendo que todas acabam por se beneficiar da melhoria de competitividade das partes;

- Cluster Regional: é similar ao Cluster industrial, embora as articulações principais ocorram no interior de um certo espaço regional, podendo essas articulações se repetirem total ou parcialmente em outras regiões do mesmo país, sendo mais relevantes os efeitos de proximidade geográfica sobre a dinâmica da interação entre os atores, nível de competitividade e inovação do conjunto.

Os Clusters apresentam características que os estimulam, como acesso a fornecedores, a sistemas de informações especializados, acesso equivalente a instituições e bens públicos, estímulo à inovação pela competição, melhoria da motivação e do desempenho das empresas participantes (KLIEMANN; HANSEN, 2003).

De acordo com Porter (1997), os Clusters afetam a maneira das empresas competirem de três formas principais: 1. aumentando a produtividade das empresas sediadas em uma mesma região; 2. indicando a direção e o ritmo da inovação que sustentam a produtividade futura; e; 3 . estimulando a formação de novas empresas necessárias ao setor, o que reforça o próprio Cluster.

Análises segundo o modelo de Clusters oferecem resultados de mapeamento das atividades econômicas desenvolvidas num arranjo produtivo regional. No entanto, o modelo não enfoca especificamente a medição de desempenho, mas as relações entre as organizações envolvidas. Exemplos de aplicação deste modelo podem ser encontrados nas análises de Porter (1999), quando aborda, no caso norte-americano, Clusters como o do Vale do Silício, as vinícolas da Califórnia, Hollywood, o Cluster médico e de equipamentos médicos da costa leste americana (Boston), entre outros.

\subsection{Supply chain (Cadeia de suprimentos)}

Este tipo de arranjo produtivo originou-se na década de 80 com aplicação nas grandes redes varejistas norte-americanas, com o objetivo de elevar a competitividade de empresas que atuam diretamente junto aos consumidores finais (CHRISTOPHER, 1997). Supply Chain, ou Cadeia de Suprimentos, está vinculada à análise das relações entre fornecedores e clientes internos das cadeias de suprimentos de materiais, insumos e componentes de um determinado arranjo produtivo, como forma de implementar uma estratégia coletiva, sempre a partir de uma empresa central. O foco de análise do arranjo está voltado ao abastecimento do mercado consumidor de forma competitiva, pela otimização do processo de transformação e de transferência de bens entre as empresas, visando a melhorar aspectos competitivos de produtos e serviços (WOOD; ZUFFO, 1998).

A progressiva expansão desta forma de arranjo empresarial (produtivo) ao longo da década de 90 deve-se, em grande parte, ao poder dessas empresas, em função do contato direto com o consumidor final. Avanços na informática de base microeletrônica e dos serviços de telecomunicações permitiram a otimização dos fluxos de atividades intra e interempresas. Neste tipo de arranjo, buscase analisar melhores formas de execução das tarefas e maneiras de racionalizá-las, eliminando atividades com implicações em níveis de estoques, interrupções na produção, custos, prazos, redução da qualidade e demais aspectos que não agregam valor ao produto ou serviço prestado, a partir do ponto de vista do cliente ou consumidor final.

O conceito de Supply Chain busca estender aos parceiros comerciais de empresas focais ou centrais (empresas que exercem a governança da cadeia) a lógica de gerenciamento por processos, visando sua integração, a formação de parcerias e mesmo a co-produção, ou seja, o desenvolvimento e produção conjunta de componentes e produtos. Este processo pode ser entendido como o desenvolvimento da função logística nas organizações, envolvendo a ligação entre as funções internas das principais empresas e, externamente a estas, incluindo os fornecedores e clientes de primeiro e segundo níveis (CHRISTOPHER, 1997).

Análises segundo o modelo de Supply Chain oferecem resultados em termos de racionalização das atividades das empresas do arranjo produtivo. O modelo contempla a medição de desempenho, mas os resultados têm foco nas empresas que exercem a governança do arranjo e suas relações com as empresas à montante e à jusante. Diversos são os exemplos de aplicação deste modelo de análise e de gestão, principalmente nos casos das grandes cadeias varejistas, nos casos de grandes fabricantes automotivos como Toyota, GM e Ford e nos casos dos fabricantes de produtos eletroeletrônicos como HewlettPackard (DORNIER et al., 2000).

\subsection{Redes de pequenas e médias empresas}

Este tipo de modelo produtivo tomou evidência a partir de estudos realizados sobre arranjos de pequenas e médias empresas (PMEs) situadas na Europa, mais especificamente no norte da Itália, envolvendo empresas do ramo metal-mecânico (CASAROTTO FILHO; PIRES, 1998). O sucesso obtido por estas empresas levou a estudos sobre 
a forma de arranjo das mesmas, as quais tinham se unido para enfrentar suas difíceis condições de sobrevivência. Tal dificuldade conduziu a uma necessidade de estabelecimento de alianças entre pequenas e médias empresas, com vistas a acessar os recursos e a tecnologia necessários à sua manutenção e sobrevivência, aumentando o poder de barganha, reduzindo custos individuais e proporcionando condições para inovação (CASAROTTO FILHO; PIRES, 1998).

Considerando as opções estratégicas existentes para esses tipos de empresas (PMEs), as alternativas básicas são constituídas pela sua inclusão em uma rede Top-Down, ou em uma rede Flexível. No formato Top-Down, existe uma grande empresa líder, a qual apresenta um conjunto de empresas menores como suas fornecedoras diretas e indiretas. No formato Flexível, a rede é formada por um consórcio de pequenas e médias empresas, no qual cada uma participa em determinado estágio do processo produtivo. Neste último tipo de rede, as empresas possuem como principal característica a sua especialização em determinada atividade do setor produtivo, enquanto as demais integrantes da rede realizam atividades complementares de transformação. A referência à flexibilidade prende-se ao fato das redes assim formadas serem constituídas por pequenas e médias empresas, as quais são mais ágeis em suas funções produtivas do que as grandes empresas verticalizadas (CASAROTTO FILHO e PIRES, 1998).

Observando-se ainda este último tipo de rede, pode-se constatar diferentes tipos de consórcios e pactos firmados entre as organizações participantes. Os principais tipos de consórcios são apresentados por Casarotto Filho e Pires (1998) como:

- Consórcio Setorial: empresas concorrentes e complementares realizam acordos que permitem ganhos de competitividade dos membros pela difusão de informações e complementaridade produtiva;

- Consórcio Territorial: reúne empresas de todos os segmentos e atividades de uma região e ocupa-se, principalmente, das atividades informativas e de promoção das empresas;

- Consórcio Específico: restringe sua ação às atividades específicas para atingir um objetivo determinado, como a exportação de produtos e bens.

Análises segundo o modelo de Redes de Pequenas e Médias Empresas permitem estabelecer ações estratégicas conjuntas. O modelo contempla a estruturação das ações coletivas do arranjo, tais como políticas, estratégias de negociação e de formação de recursos humanos. Exemplos de aplicação desses tipos de arranjos têm se tornado cada vez mais comuns, inclusive no Brasil, conforme atesta o Programa Redes de Cooperação do Governo do
Estado do RS (VERSCHOORE, 2004) e outros (AMATO NETO, 2000). No entanto, a avaliação de desempenho é um tópico que ainda carece de maior profundidade neste tipo de arranjo produtivo.

\section{Estratégias e competitividade em arranjos produtivos}

As abordagens tradicionais de formulação de estratégias e de avaliação da competitividade, baseadas no foco individual das empresas, têm se mostrado inadequadas no atual contexto globalizado e de acirrada competição. O crescente número de fusões de empresas, estabelecimento de parcerias e outras formas de relações interempresariais, principalmente os arranjos produtivos, demonstra a crescente influência das relações externas às empresas, comparativamente às condicionantes internas, no estabelecimento de estratégias competitivas e no alcance dos resultados. Neste contexto, verifica-se cada vez mais a adoção de estratégias coletivas nos arranjos empresariais, as quais têm resultado em técnicas para padronização de qualidade, troca de informações e condições de fornecimento (CHRISTOPHER, 1997). Portanto, a adoção de estratégias coletivas nos arranjos está baseada no alinhamento de interesses e objetivos dos integrantes, o que resultará em ganhos ou perdas para todo o arranjo produtivo (PECK; JUTTNER, 2000).

Em um arranjo produtivo encontram-se empresas estreitamente relacionadas pela compra e venda de produtos e serviços, o que muitas vezes também induz à adoção de estratégias coletivas visando ao aumento de sua competitividade (FERRAZ; KUPFER; HAGUENAUER, 1996). Estes arranjos podem ultrapassar as barreiras geográficas do país de origem das empresas envolvidas nas relações comerciais. Para a análise de arranjos produtivos considerando o atual processo de globalização, com empresas atuando em diferentes países, destacam-se aspectos como (KAPLINSKY; MORRIS, 2001):

1. a crescente divisão de trabalho e a dispersão global da produção dos componentes, levando a sistemática competitiva a tornar-se cada vez mais importante;

2. a eficiência na produção é somente uma condição necessária para atingir, com sucesso, os mercados globais;

3. a entrada em mercados globais requer um entendimento de fatores dinâmicos dentro de toda a cadeia produtiva, que afetam o desempenho do arranjo junto ao mercado consumidor final.

A compreensão dos fatores dinâmicos referidos e a necessidade de atingir uma posição competitiva conduzem à busca do aumento da eficiência coletiva de produção. Assim, a análise das cadeias produtivas precisa ser vista 
sob uma óptica sistêmica, pois representa um conjunto de componentes interativos, incluindo os diversos sistemas produtivos, fornecedores de insumos e serviços, indústrias de processamento e transformação, agentes de distribuição e comercialização, além do mercado consumidor final (CASTRO, 2003).

A competição internacional também ocorre entre arranjos produtivos e entre cadeias produtivas. Numa economia aberta, é essencial que sejam identificados fatores e condicionantes da competitividade de cada cadeia produtiva, para que se possa entender as razões do seu desempenho. Segundo Coutinho e Ferraz (1995), a competitividade sistêmica, nesta perspectiva, deve ser entendida como resultante de fatores que atuam em três dimensões:

- Empresarial: fatores ou condicionantes de domínio das empresas, incluindo questões como custo/preço (produtividade), qualidade, inovação, marketing, capacidade produtiva e sua relação com custos e preços (produtividade), capacidade para inovação e sua relação com qualidade e diferenciação de produtos, a capacitação dos recursos humanos, a estratégia e a gestão das empresas;

- Estrutural: fatores ou condicionantes relacionados ao mercado, à tecnologia, à configuração da indústria e sua relação com a escala de produção e à dinâmica específica da concorrência no setor ou cadeia analisada;

- Sistêmica: fatores ou condicionantes macroeconômicos, como mercados internacionais, avanço do conhecimento, infraestruturais, fiscais, financeiros, políticos e institucionais, que mais diretamente influenciam no desempenho geral ou específico do arranjo ou da cadeia em algumas das variáveis econômicas analisadas, tais como mão de obra contratada, comércio exterior, custos da estrutura produtiva ou obstáculos que essa mesma dimensão impõe à superação dos problemas competitivos identificados no plano micro (empresarial) e setorial (estrutural).

Considerando a abordagem da competitividade sistêmica, o Instituto de Desenvolvimento Alemão (GDI - German Development Institute) desenvolveu uma proposta de análise e abordagem sistêmica da competitividade, visando à identificação da situação competitiva de uma região e dos arranjos produtivos nela inseridos. $\mathrm{O}$ modelo contempla quatro níveis de análise, os quais são compostos por (ESSER et al.,1996): 1. Nível Micro; 2. Nível Meso; 3. Nível Macro; e 4. Nível Meta.

1. Nível Micro: envolve as melhores práticas organizacionais como fatores determinantes para a competitividade, a gestão efetiva de inovações organizacionais e a gestão tecnológica. Assim, busca-se o fortalecimento dos elos entre as atividades das empresas, bem como dos elos externos (entre empresas).
2. Nível Meso: tem foco nas políticas seletivas (não abrangentes), buscando remover entraves específicos para empresas em termos de infraestrutura (tais como transportes, energia e telecomunicações) que afetam a competitividade, criação de políticas dirigidas à educação para pesquisa tecnológica, formulação de políticas comerciais e sistemas normativos (normas ambientais, técnicas, de segurança) que contribuam para a criação de vantagens competitivas nacionais;

3. Nível Macro: contempla aspectos macroeconômicos que garantem condições necessárias para o desenvolvimento da competitividade. Desta forma, os fatores essenciais que deverão existir neste nível, para permitir a melhoria da competitividade, são: estabilidade do ambiente macroeconômico, condições financeiras favoráveis, política de concorrência que impeça a formação de monopólios, política cambial adequada e políticas fomentadoras de integração;

4. Nível Meta: aborda aspectos referentes ao desenvolvimento da capacidade nacional de condução de estratégias para o setor. Assim, a capacidade dos atores em estabelecer um padrão de organização jurídica, política, econômica e macrosocial tende a permitir que se agrupem, potencializando as vantagens nacionais de inovação, crescimento econômico e competitividade, desencadeando processos sociais de aprendizagem e comunicação;

As abordagens anteriores (COUTINHO; FERRAZ, 1995; ESSER et al.,1996) possuem um enfoque denominado mesoanalítico, centrado na abordagem do arranjo produtivo estudado. Suas relações internas e as relações de causa-e-efeito são vinculadas, constituindo assim uma diferenciação em relação à macroanálise, típica dos estudos da teoria econômica e à microanálise, centrada no escopo da teoria da administração de empresas. Com base no princípio sistêmico, a competitividade é fruto da interdependência dos diversos fatores, em que os arranjos produtivos mais competitivos são aqueles nos quais os atores possuem uma percepção ampliada da sua situação competitiva, identificando problemas comuns e agindo de forma integrada para a sua solução. Contudo, o maior benefício do estudo dos arranjos produtivos é a possibilidade de ampliação da compreensão do contexto no qual as empresas estão inseridas, fazendo com que as mesmas adotem uma abordagem sistêmica de sua competitividade. Desta forma, é possível perceber as interrelações existentes entre os diferentes elos de um arranjo produtivo, incluindo os pontos de estrangulamento da competitividade do arranjo e das próprias empresas, culminando num esforço conjunto para produzir benefícios para todos os envolvidos. 


\section{Modelos de avaliação de desempenho de arranjos produtivos}

A partir do enfoque sistêmico abordado para a análise da competitividade dos arranjos produtivos, uma questão relevante neste contexto diz respeito à avaliação de desempenho das empresas integrantes destes aglomerados e do arranjo como um todo. A seguir, são apresentadas algumas propostas deste tipo de medição de desempenho. Deve ser salientado que a maioria dos modelos desenvolvidos para a avaliação de desempenho de arranjos produtivos ao longo dos últimos anos, quase que em sua totalidade, são direcionados para cadeias de suprimentos, ou Supply Chain, o que, de certa forma, limita sua eventual aplicação, de forma generalizada, aos demais tipos de arranjos estudados.

\subsection{Avaliação de desempenho de cadeias de suprimentos}

De acordo com Beamon (1999), a seleção de medidas de desempenho é uma etapa crítica no desenvolvimento e avaliação de qualquer sistema ou processo produtivo. No caso específico de Supply Chain (cadeia de suprimentos), este aspecto é dificultado pelas diversas etapas do processo de transformação da matéria-prima em produto final, sendo cada uma delas composta por diversas empresas ou empreendimentos.

Abordando os sistemas de avaliação de desempenho desenvolvidos até o presente, Beamon (1999) constata que os mesmos são limitados com relação ao escopo ou falham por tentar utilizar medidas singulares (únicas) de avaliação de desempenho, fatos que restringem a avaliação ou ignoram importantes relações entre alternativas de avaliação de desempenho.

Considerando este contexto, Beamon (1999) propõe uma estrutura para medição de desempenho, incluindo objetivos organizacionais estratégicos e atendendo às características dos setores produtivos, composta por medidas dos Recursos utilizados (R), medidas dos resultados (Outputs) alcançados (O) e medidas da Flexibilidade (F) da cadeia de suprimentos analisada. De acordo com a proposta formulada, a autora cita que as medidas de recursos utilizados (R) devem focar a eficiência do uso para atender os objetivos do sistema e evidencia a importância de observar as relações de causa-e-efeito existentes entre os três tipos de medidas sugeridas.

A proposta formulada apresenta medidas típicas do uso de recursos, tais como: custo total, custos de distribuição, custos de produção, inventários e retorno sobre o investimento. Considera também medidas de resultados da cadeia de suprimentos como índices de vendas, lucro, grau de preenchimento dos pedidos, entregas no prazo, falta de estoque/não atendimento de pedidos, tempo de resposta ao consumidor, lead time (tempo de atravessamento) de produção, erros de embarque e reclamações de clientes.

A Flexibilidade (F), segundo Beamon (1999), é usada como medida da habilidade (capacidade) do sistema de absorver ou se adequar às incertezas do meio e da demanda. Esta medida se divide em: flexibilidade de volume, flexibilidade de entrega, flexibilidade de mix (composição) de produção e flexibilidade de novos produtos.

Outro modelo para avaliação da competitividade é apresentado por Holmberg (2000), que parte da discussão dos fundamentos da gestão da cadeia de suprimentos (SCM ou Supply Chain Management), para abordar a questão da avaliação de desempenho. Segundo o autor, a cadeia de suprimentos deve ser vista como uma entidade única e não de forma fragmentada. Como decorrência, a cadeia demanda um processo de planejamento estratégico integrado, o qual requer uma nova perspectiva de sistema e não apenas de puro e simples relacionamento entre as partes.

Holmberg (2000) acrescenta que a falta de conexão entre estratégias e medidas de desempenho voltadas para o foco interno das empresas, muitas vezes contribui para a sub-otimização da cadeia como um todo. Aborda, também, a utilização pelas empresas de medidas de desempenho isoladas (individuais) e incompatíveis com as de outras organizações da cadeia. Outro ponto igualmente relevante, na visão do autor, é a fragmentação interna das informações nas empresas e a fragmentação externa das informações (o que mostra o baixo nível de troca de informações e dados entre empresas integrantes de cadeias de suprimentos).

A partir destas considerações, Holmberg (2000) formula uma proposta genérica de estrutura de um sistema de avaliação de desempenho de cadeias de suprimentos. Para tanto, considera o modelo desenvolvido pela cadeia de varejo de móveis IKEA, onde foi implantado um sistema envolvendo as informações dos pontos de venda e troca de informações referentes a custos, prazos e níveis de estoques, com outras empresas à montante na cadeia de suprimentos (fornecedores), o que redundou numa melhoria da gestão do sistema como um todo.

\subsection{Estruturação de medidas de desempenho de cadeias de suprimentos}

De acordo com Lambert e Pohlen (2001), diversos fatores têm contribuído para a dificuldade em estabelecer medidas de desempenho para as cadeias de suprimentos. Como dificuldades, os autores destacam: 1. a falta de diretrizes globais para a gestão das cadeias; 2 . a complexidade de estabelecer unidades de medida comuns para 
as diversas empresas; 3. a falta de padrão para trocas de informações entre as empresas da cadeia; 4. a falta de definição sobre a qualidade e o desempenho do produto para todas as empresas da cadeia, a partir do ponto de vista do consumidor final. Os autores constatam que a maior parte das medidas de desempenho sugeridas para cadeias de suprimentos são, na realidade, medidas de desempenho das operações logísticas internas das empresas. Portanto, as medidas de desempenho atualmente empregadas possuem foco na performance individual das empresas, por vezes conflitantes entre si, conduzindo a ineficiências na cadeia como um todo.

A partir dessas considerações, os autores propõem uma estrutura para o desenvolvimento de um sistema de medição de desempenho para cadeias de suprimentos. Esta estrutura contempla o objetivo geral de maximizar os resultados ao consumidor final da cadeia, bem como os resultados individuais das empresas participantes. A mesma consiste de sete etapas (LAMBERT; POHLEN, 2001):

1. mapear a cadeia de suprimentos para identificar as relações críticas;

2. analisar cada relação da cadeia e seu impacto sobre o produto final;

3. desenvolver uma definição (análise) de perdas e lucros para cada relação;

4. readequar os processos da cadeia de suprimentos que se mostrem com baixo desempenho;

5. alinhar as medidas de desempenho não financeiras com as medidas de perdas e lucros;

6. comparar os resultados das medidas entre as empresas dos diversos elos produtivos e replicar as etapas anteriores da estrutura para as outras relações (elos) da cadeia de suprimentos problemáticos;

7. analisar os processos em cada elo (relação) da cadeia de suprimentos, identificando a agregação de valor de cada um destes elos.

Com base nessas 7 etapas de análise dos processos das cadeias de suprimentos, os autores identificam que estes poderão ser alinhados de forma a produzir maior valor para os consumidores finais, além de maior lucratividade e valor para as atividades de cada empresa participante, contribuindo assim para o aumento de competitividade da cadeia.

Segundo Lambert e Pohlen (2001), esta sistemática de estruturação de um sistema de medidas de desempenho poderia ser aplicado a qualquer cadeia de suprimentos estabelecida, tendo ela como empresa focal o grande varejo (redes supermercadistas) ou empresas fabricantes de produtos de alto valor agregado (fabricantes de eletroeletrônicos, automóveis, computadores e outros).

\subsection{Análise crítica dos modelos de avaliação de desempenho apresentados}

Considerando os modelos de avaliação de desempenho apresentados anteriormente, os quais focam a medição de cadeias de suprimentos (um dos tipos mais comuns de arranjos produtivos), pode verificar-se que:

- os modelos utilizam uma abordagem microanalítica, focada no alinhamento da estratégia das demais empresas da cadeia à estratégia de uma empresa central (focal) com forte papel no mercado;

- a proposta de medição de Beamon (1999) apresenta caráter mais operacional, focado no atendimento dos requisitos do mercado consumidor final da cadeia;

- a sistemática proposta por Lambert e Pohlen (2001) limita-se a estabelecer as principais relações de causa-eefeito existentes nos processos de transformação dos elos da cadeia de suprimentos como forma de avaliar a contribuição para os resultados, mas não identifica variáveis ou dimensões da medição;

- o alinhamento das medidas de desempenho entre as diversas organizações da cadeia de suprimentos, como proposto por Holmberg (2000), constitui um aspecto básico para a integração da medição de desempenho competitivo de arranjos produtivos, sem, no entanto, propor indicadores específicos para a análise de desempenho;

- a comparação do desempenho da cadeia frente a concorrentes e à avaliação dos benefícios obtidos pelos diversos elos da cadeia de suprimentos, apesar de mencionados pelos diferentes autores, não constituem aspectos fundamentais dos modelos analisados.

Considerando-se a questão de avaliação da competitividade sistêmica no cenário mesoanalítico, evidencia-se a oportunidade e necessidade de abordar análises também relevantes, tais como o desempenho competitivo do arranjo junto ao mercado consumidor, a sustentabilidade competitiva das empresas do arranjo e os direcionadores competitivos, com foco nas relações (processos) entre as empresas intepresas integrantes do arranjo. 


\section{Considerações metodológicas do estudo}

O presente estudo tem caráter exploratório e qualitativo e analisa o tema da medição de desempenho competitivo de arranjos produtivos.

De acordo com Malhotra (2001), o objetivo da pesquisa exploratória é prover critérios e compreensão sobre o tema estudado, e possui como características ter processo de pesquisa flexível e não estruturado, focar amostras pequenas e não representativas, envolver análise qualitativa de dados e constatações experimentais. Também segundo esse autor, pesquisas qualitativas buscam alcançar uma compreensão qualitativa das razões do fenômeno analisado, utiliza pequeno número de casos, possui coleta de dados não estruturada, análise não estatística de dados e desenvolve uma compreensão inicial do fenômeno.

Assim, a partir da revisão bibliográfica, são conduzidas análises teórico-conceituais sobre o tema em epígrafe. Na sequência, é proposto o desenvolvimento de um modelo teórico para avaliar o desempenho competitivo de arranjos produtivos, tomando por base as análises realizadas. É também avaliada a adequabilidade do modelo proposto, através da estratégia de estudo de caso, pela sua aplicação parcial ao arranjo produtivo coureiro-calçadista do Vale dos Sinos no RS.

Yin (2005, p. 32) define estudo de caso como sendo "uma investigação empírica que investiga um fenômeno contemporâneo dentro do seu contexto da vida real, especialmente quando os limites entre o fenômeno e o contexto não são claramente definidos". O mesmo autor ainda salienta que é mais provável que a estratégia de estudo de caso seja apropriada a questões do tipo 'como' e 'por que', sendo sua tarefa inicial precisar a natureza das questões de estudo nesse sentido.

Como instrumentos de coleta de dados foram utilizados documentos disponíveis sobre o referido arranjo, foram realizadas entrevistas com especialistas do setor e representantes das empresas do arranjo, fazendo uso de roteiros semiestruturados.

\section{Modelo para avaliação sistêmica do desempenho competitivo de arranjos produtivos}

A partir do exposto, a presente proposta considera como elementos relevantes para avaliação sistêmica do desempenho competitivo de arranjos produtivos os seguintes aspectos: o desempenho competitivo do arranjo junto ao mercado final, a sustentabilidade das empresas do arranjo e os direcionadores competitivos, envolvendo os processos interempresariais.

Para que se torne possível essa avaliação, apresenta-se um modelo preliminar para apoiar a avaliação sistêmica do desempenho competitivo de arranjos produtivos. A aplicação desse modelo pressupõe o desenvolvimento dos seguintes passos:

1. Definição do segmento produtivo e do negócio a ser analisado;

\section{Mapeamento e análise preliminar da cadeia;}

3. Identificação do desempenho competitivo (indicadores) do arranjo no mercado;

4. Desdobramento das medidas de desempenho competitivo do arranjo, caracterizando a sustentabilidade das empresas (indicadores);

5. Desdobramento das medidas de desempenho competitivo da cadeia, caracterizando os processos de negócio do arranjo, os direcionadores competitivos (indicadores);

6. Estabelecimento de banco de dados de todas as medidas de desempenho;

7. Identificação e análise do elo fraco do arranjo;

8. Realinhamento dos processos do elo fraco;

9. Retorno à etapa de identificação do novo elo fraco.

Considera-se que o ideal seja a realização de todas as etapas acima enunciadas para a completa análise de competitividade de arranjos produtivos. No entanto, levando em conta o período eventualmente necessário para a efetiva implantação do modelo proposto, acredita-se que, em muitos casos, isso venha a ser realizado por etapas sucessivas.

Buscando permitir uma melhor visualização do modelo proposto, a Figura 1 esclarece as relações de causa-e-efeito envolvidas na avaliação do desempenho competitivo pretendida.

Tendo em foco o desempenho competitivo, a mesoanálise da competitividade de um arranjo produtivo deve basearse no seu desempenho junto ao mercado consumidor final (elo final da cadeia), identificando os fatores competitivos que os usuários finais valorizam o seu grau de alcance. A compreensão das características do mercado consumidor, suas demandas e potencialidades, permite verificar as estratégias adotadas, em termos da gover-nança do arranjo, e sua adequação ao cenário existente. A constatação da existência de relacionamento entre as prioridades 
competitivas dos diversos elos do arranjo propicia identificar, como decorrência, o alinhamento estratégico das diversas empresas integrantes da mesma.

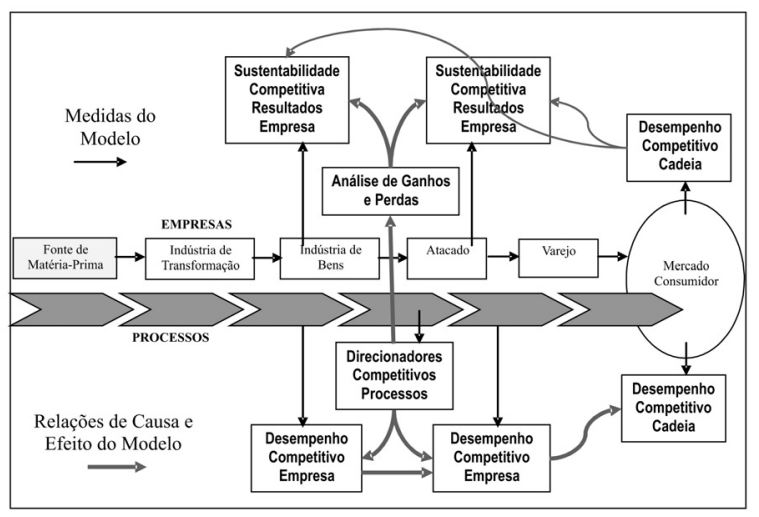

Figura 1 - Esquema do Modelo para Avaliação Sistêmica do Desempenho Competitivo de Arranjos Produtivos Fonte: Adaptado de Hansen (2004).

Considerando a sustentabilidade, a mesoanálise da competitividade do arranjo deve enfocar a condição de sobrevivência e manutenção das empresas, como participantes do arranjo produtivo. Assim, devem ser analisados aspectos relacionados ao grau de sucesso das empresas nas suas atividades, envolvendo resultados econômicofinanceiros, capacidade produtiva, volumes de produção, participação no mercado e fatores que permitam avaliar a consistência de atuação das empresas. Esta interpretação parece fundamental à luz do entendimento da competitividade sistêmica, pois implica simultaneamente o atendimento dos requisitos do mercado consumidor (clientes) e a sobrevivência e manutenção das empresas.
Quanto à abordagem dos direcionadores competitivos, busca-se enfocar as relações entre as empresas integrantes do arranjo e destas com entidades externas. Assim, no que tange às relações entre as empresas, o enfoque de análise é semelhante ao proposto por Lambert (2001) e centrado na avaliação dos oito processos interempresariais do $S C M$, envolvendo o grau de integração, grau de gestão e o do fluxo de informações que os viabiliza. De forma semelhante, no que tange às relações do arranjo com outras instituições de apoio direto, também devem ser avaliados os processos de apoio que afetam direta e significativamente a competitividade do arranjo em estudo. Os direcionadores competitivos, conforme observado, apesar de envolverem a análise da situação presente, permitem evidenciar potenciais futuros da cadeia e estimar sua competitividade (KLIEMANN; HANSEN, 2003).

Buscando uma visualização mais objetiva da avaliação sistêmica do desempenho competitivo de arranjos produtivos, Hansen (2004) propõe no Quadro 1 um resumo dos aspectos abordados anteriormente. O Quadro 2, por sua vez, ilustra exemplos de indicadores de desempenho a serem utilizados em cada perspectiva de avaliação.

A partir da existência de medidas de desempenho competitivo, de sustentabilidade das empresas e dos direcionadores do desempenho, torna-se possível estabelecer um benchmarking (padrões e referências comparativas) competitivo, que auxilie a avaliar lacunas e aspectos a serem melhorados no desempenho do arranjo analisado, visando a elevar sua competitividade, tanto individual como coletivamente.

\begin{tabular}{|c|l|l|}
\hline Tipo de Análise & \multicolumn{1}{|c|}{ Foco da Análise } & \multicolumn{1}{c|}{ Objetivos da Análise } \\
\hline $\begin{array}{c}\text { Desempenho } \\
\text { Competitivo }\end{array}$ & $\begin{array}{l}\text { Fatores competitivos no mercado e } \\
\text { estratégia de governança do arranjo; } \\
\text { Fatores competitivos das empresas do } \\
\text { arranjo e estratégia das empresas }\end{array}$ & $\begin{array}{l}\text { Definir a competitividade do arranjo no mercado; } \\
\text { Avaliar a estratégia e governança empregadas; } \\
\text { Avaliar o alinhamento estratégico das empresas; }\end{array}$ \\
\hline $\begin{array}{c}\text { Sustentabilidade } \\
\text { Competitiva }\end{array}$ & $\begin{array}{l}\text { Resultado final do arranjo; } \\
\text { Resultado das empresas do arranjo; }\end{array}$ & $\begin{array}{l}\text { Avaliar a sustentação, manutenção } \\
\text { e sobrevivência do arranjo e empresas integrantes; }\end{array}$ \\
\hline $\begin{array}{c}\text { Direcionadores } \\
\text { Competitivos }\end{array}$ & $\begin{array}{l}\text { Relações interempresariais; } \\
\text { Relações entre empresas } \\
\text { e instituições de apoio; }\end{array}$ & $\begin{array}{l}\text { Avaliar o desempenho dos processos } \\
\text { interempresariais; } \\
\text { Avaliar processos de apoio institucional ao arranjo; }\end{array}$ \\
\hline $\begin{array}{c}\text { Benchmarking } \\
\text { Competitivo }\end{array}$ & $\begin{array}{l}\text { Dados do desempenho competitivo; } \\
\text { Dados dos direcionadores; } \\
\text { competitivos. }\end{array}$ & $\begin{array}{l}\text { Comparar o desempenho do arranjo e empresas } \\
\text { com os concorrentes; } \\
\text { Comparar o desempenho dos processos do arranjo } \\
\text { com os dos concorrente. }\end{array}$ \\
\hline
\end{tabular}

Quadro 1 - Resumo da proposta de modelo para avaliação sistêmica do desempenho competitivo de arranjos produtivos Fonte: Adaptado de Hansen (2004). 


\begin{tabular}{|c|c|}
\hline Tipo de Análise & Indicadores Propostos \\
\hline Desempenho Competitivo & Preços, prazos, confiabilidade, qualidade, flexibilidade, disponibilidade, outros. \\
\hline $\begin{array}{c}\text { Sustentabilidade } \\
\text { Competitiva }\end{array}$ & $\begin{array}{c}\text { EVA, retorno sobre investimento, custo total por produto (envolvendo produção, } \\
\text { transporte, estoques), receita, impacto ambiental, responsabilidade social, outros. }\end{array}$ \\
\hline $\begin{array}{c}\text { Direcionadores } \\
\text { Competitivos }\end{array}$ & $\begin{array}{c}\text { Atendimento de pedidos, não atendimento de pedidos, erros de pedidos, volumes } \\
\text { insuficientes, níveis de estoques, falta de informações, atrasos de informações, outros. }\end{array}$ \\
\hline Benchmarking Competitivo & Comparação dos indicadores anteriores com os de outros arranjos. \\
\hline
\end{tabular}

Quadro 2 - Exemplos de indicadores de desempenho para o modelo para avaliação sistêmica do desempenho competitivo de arranjos produtivos

Fonte: Adaptado de Hansen (2004).

O Quadro 2 identifica alguns indicadores típicos de cada um dos elementos propostos para a avaliação sistêmica do desempenho competitivo de arranjos produtivos que, no entanto, não devem ser interpretados como extensivos e capazes de cobrir todas as necessidades levantadas, mas sim constituírem um exemplo ilustrativo.

Na sequência, introduz-se o arranjo produtivo foco de estudo e, após, discute-se uma aplicação parcial do modelo acima proposto a este caso real.

\section{$7 \mathrm{O}$ arranjo produtivo coureiro- calçadista do Vale dos Sinos - RS}

Considerando a caracterização deste arranjo produtivo como Cluster, Fensterseifer e Gomes (1995, p.26) citam que:

No Rio Grande do Sul, devido à concentração geográfica das atividades do complexo coureiro-calçadista do Vale dos Sinos, este se constitui em um verdadeiro distrito industrial (rede de indústrias afins fisicamente próximas umas das outras), ou num Cluster, conforme definido por Porter (1990). A concentração geográfica de indústrias afins representa, segundo Porter (1990), um dos fatores determinantes da competitividade do setor industrial na Nação. A proximidade física das empresas proporciona 'economias de aglomeração', que contribuem para a eficiência coletiva do setor.

Exportando para mais de 100 países e com uma produção anual de 550 milhões de pares, o Brasil é o terceiro maior fabricante mundial de calçados, sendo o líder mundial na fabricação de calçados femininos (ASSINTECAL, 2006). Atualmente existem mais de 1.600 tipos de componentes de calçados fabricados no Brasil (químicos, metais, solados, cadarços, palmilhas etc). Este volume de produção e seu posicionamento global na produção de calçados devem-se a aproximadamente 1.000 empresas atuando neste setor, as quais geram em torno de 85.000 empregos diretos (ASSINTECAL, 2006). Estes são distribuídos em doze polos calçadistas no país, sendo que o Vale dos Sinos é atualmente considerado o maior cluster calçadista do mundo (ASSINTECAL, 2006).

A expressão Vale dos Sinos é utilizada para referir um conjunto de municípios que se localizam em torno do rio que lhe dá o nome (Rio dos Sinos). No caso em análise, a produção de calçados localiza-se em cerca de 21 municípios dessa região do Rio Grande do Sul (RS). Esse cluster caracteriza-se pelo foco num produto final específico (calçado feminino), com divisão de tarefas produtivas, especialização entre empresas, subcontratação de partes da produção, importância de pequenas empresas, disponibilidade de mão de obra qualificada e pela presença de serviços de apoio tecnológico (RUAS, 1995).

O Cluster coureiro-calçadista do RS concentra a etapa de manufatura do processo total de transformação. Assim, a cadeia produtiva (ou Filière) coureiro-calçadista é mais ampla, possuindo elos externos à região do Vale dos Sinos, os quais envolvem a produção, obtenção da matériaprima, distribuição e comercialização dos produtos acabados. A Figura 2 mostra uma representação simplificada da cadeia coureiro-calçadista do RS.

De forma geral, observa-se que as empresas Cluster desenvolvem estratégias individuais focadas no baixo custo de insumos e produtos (posicionamento de liderança em custos). Com estratégias produtivas focadas na eficiência interna, as empresas buscam vantagens competitivas frente aos concorrentes do próprio Cluster. As estratégias individuais são baseadas nas pressões externas e exigências das grandes empresas, nas quais cada fornecedor busca atender as demandas da melhor forma possível (HANSEN et al., 2003).

Quanto ao desenvolvimento de estratégias coletivas, as empresas costumam considerar somente seus fornecedores e clientes mais próximos. As relações interempresariais possuem caráter informal e são baseadas no histórico da relação. Além disso, as demandas e o tipo de componentes são sazonais, com base em aspectos como moda e estações do ano (HANSEN et al., 2003) . 
A interpretação reinante no complexo indica que a competitividade das empresas é fortemente afetada por carências gerenciais nas mesmas e pela política tributária e fiscal do país, além da questão do câmbio. Observa-se, de forma geral, um enfoque competitivo individualista, que não considera as vantagens de uma atuação coletiva, tampouco os eventuais benefícios decorrentes da mesma. Constatase, ainda, a falta de uma visão mais abrangente do cenário competitivo, em que as empresas visualizam os concorrentes internos do Cluster, mas não os externos (HANSEN et al., 2003). A seguir, é discutida a aplicação do modelo proposto a uma parte do arranjo produtivo em análise.

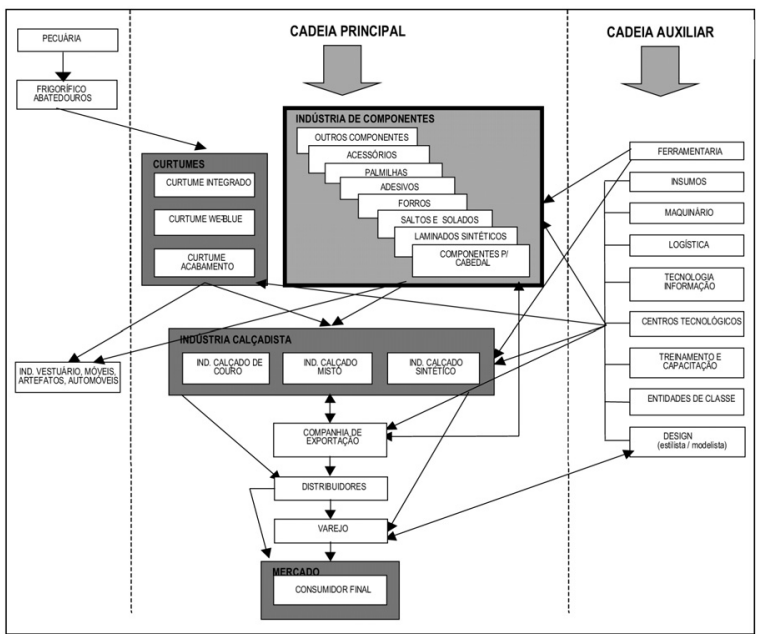

Figura 2 - Representação simplificada da cadeia coureirocalçadista do RS

Fonte: Adaptado de Hansen, 2004.

\section{Aplicação experimental do modelo de avaliação sistêmica do desempenho competitivo de arranjos produtivos proposto}

O segmento analisado é representado pelas empresas que atuam na área de fabricação de componentes para couro, calçados e artefatos. O mesmo é constituído por fornecedores das empresas fabricantes de calçados no Estado do RS e fora dele, em nível nacional e internacional.

O modelo proposto para avaliação sistêmica do desempenho competitivo de arranjos produtivos insere-se em um projeto amplo de melhoria de competitividade do segmento de componentes, o qual conta com a participação de entidades de classe e empresas vinculadas. O projeto foi iniciado em março de 2004 e, dentre os diversos produtos a serem obtidos, destacam-se: 1 . um relatório dos indicadores de competitividade da indústria de componentes para couro e calçados do Vale dos Sinos, que permita a comparação com indicadores de outros polos fabricantes, incluindo propostas para a melhoria da competitividade e; 2. sistema informatizado para o gerenciamento dos indicadores da indústria de componentes para couro e calçados.

Lembrando as etapas propostas para o modelo de avaliação, descritas no item 6 , apresenta-se a seguir o estágio atual de desenvolvimento do mesmo aplicado ao caso prático em estudo:

1. Definição do segmento produtivo e do negócio a ser analisado - trata-se do segmento de componentes e acessórios para couro, calçados e artefatos;

2. Mapeamento e análise preliminar da cadeia - este mapeamento já foi desenvolvido através de diversas pesquisas, como relatado no item 7 anterior;

3. Identificação do desempenho competitivo (indicadores) do arranjo no mercado - foram desenvolvidos indicadores voltados à competitividade do arranjo, da concorrência e de fatores socioeconômicos externos ao mesmo que o afetam (ver Figura 3);

4. Desdobramento das medidas de desempenho competitivo do arranjo, caracterizando a sustentabilidade das empresas (indicadores) - foram desenvolvidos indicadores voltados aos resultados das empresas do arranjo (ver Figura 3);

5. Desdobramento das medidas de desempenho competitivo da cadeia, caracterizando os processos de negócio do arranjo, os direcionadores competitivos (indicadores) - foram desenvolvidos indicadores voltados aos processos e fornecedores do elo do arranjo (ver Figura 3);

6. Estabelecimento de banco de dados de todas as medidas de desempenho - foi estruturado um banco de dados junto ao site da entidade de classe relacionada ao arranjo;

7. Identificação e análise dos elos fracos da cadeia - a análise dos resultados dos indicadores do modelo proposto encontra-se ainda em sua fase inicial;

8.e 9. As etapas 8 e 9 ainda não foram realizadas no projeto aqui descrito.

A Figura 3 apresenta o esquema da avaliação de desempenho competitivo desenvolvido para as empresas de componentes do arranjo calçadista com base no modelo proposto.

Com relação ao processo de implantação prática do modelo para avaliação sistêmica do desempenho competitivo do arranjo, alguns comentários são necessários. $\mathrm{O}$ sistema de avaliação de desempenho é informatizado, tendo por base o banco de dados das empresas associadas à entidade de classe. Foram desenvolvidos módulos complementares sobre o banco de dados original, onde 
as informações coletadas de forma periódica são armazenadas e tratadas. A coleta das informações das empresas é realizada mensalmente e disponibilizada no website para acesso pelas empresas participantes. No estágio atual do projeto, dois segmentos de empresas filiadas ao Projeto (entidade de classe) estão participando de forma efetiva: o segmento de matrizarias e o segmento de adesivos, envolvendo 15 empresas.

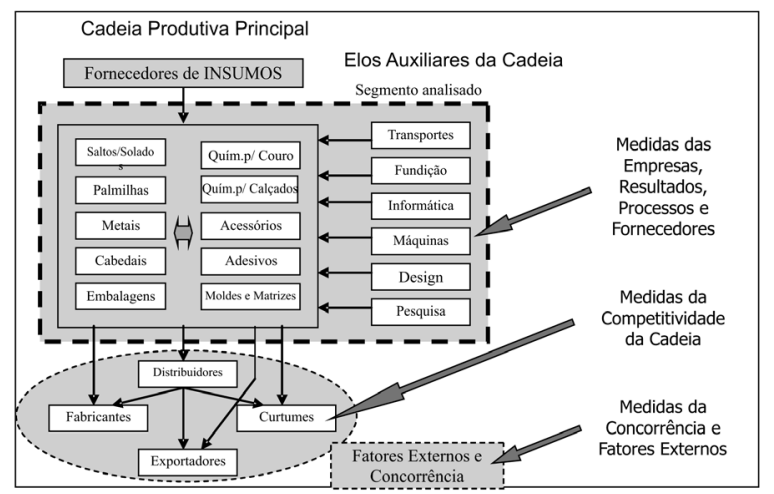

Figura 3 - Estrutura para avaliação sistêmica do desempenho competitivo do arranjo calçadista

A expectativa é de extensão do projeto para todos os demais segmentos da cadeia de componentes, a partir da conscientização, motivação e obtenção de resultados nos dois segmentos iniciais. Considerando as características das empresas do arranjo analisado, em grande parte de pequeno porte, o processo de implantação dos indicadores vem sendo realizado progressivamente em etapas, como descrito no Quadro 3. Certas dificuldades foram observadas durante a implantação inicial do projeto, tais como a dificuldade na coleta de dados, visto que algumas das empresas participantes possuem estrutura reduzida e não usam estas informações para sua gestão atual.
Durante as primeiras coletas de dados, parte das empresas não possuía os dados no formato exigido pelo sistema, ou mesmo não controlava este tipo de informação. Certo receio também foi demonstrado por algumas empresas, por terem de fornecer determinadas informações que julgavam privilegiadas, o que dificultou a coleta dos dados. Paralelamente, alguns benefícios do projeto já começaram a surgir no seu estágio inicial de implantação. Algumas empresas, não acostumadas a coletar dados específicos de desempenho, passaram a valorizar mais as informações levantadas, além de sistematizar sua coleta e, gradativamente, passar a utilizar as mesmas no seu processo decisório. Parte das empresas não possuía referenciais comparativos para sua atuação e iniciou, com a utilização dos resultados disponíveis no sistema, a realizar ações de benchmarking (comparação de seus resultados e processos com aqueles de empresas similares) e definir ações de melhoria.

A Figura 4 ilustra alguns dos resultados produzidos pelo sistema de avaliação de desempenho competitivo da cadeia. A título de ilustração, seguem alguns dos indicadores que poderão ser obtidos pelo sistema, quando de sua total implantação, a saber: 1. Produtividade: faturamento anual pelo número de funcionários na produção; 2. Lucratividade: evolução nos últimos anos; 3. Faturamento: evolução nos últimos anos; 4. Concentração: número de clientes que representam $50 \%$ das vendas; 5. Exportação: $\%$ das vendas com este destino ao longo do tempo; 6 . Mercado: \% de vendas nos mercados onde atua (RS, Brasil e Exterior); 7. Inovação: \% do faturamento originado nos novos produtos desenvolvidos; 8 . Compras: \% de compras originadas no setor e fora deste; 9 . Valor agregado indireto: $\%$ do faturamento gasto com compra de matéria-prima; 10. Lead Time: dias decorridos entre o pedido e a entrega do mesmo ao cliente; 11 . Ociosidade: $\%$ de produção realizada frente à capacidade instalada.

\begin{tabular}{|c|c|c|c|}
\hline \multirow{2}{*}{ Etapa } & Tipos de Indicadores & Período & Coleta \\
\hline \multirow{2}{*}{1} & Resultados das empresas do arranjo & Mensal & Junto às empresas do arranjo \\
\hline \multirow{2}{*}{2} & Resultados dos clientes do arranjo & Semestral & Junto a alguns clientes do arranjo \\
\cline { 2 - 4 } & Resultados dos fornecedores do arranjo & Semestral & Juntos às empresas do arranjo \\
\hline 3 & Resultado de fatores externos e concorrência & Semestral & Pesquisa pela entidade \\
\hline
\end{tabular}




\section{Conclusões}

A partir do exposto, percebe-se que a expansão das diversas formas de arranjos produtivos constitui hoje uma realidade, parecendo indicar uma nova tendência de relações organizacionais e interorganizacionais.

Também é possível perceber o fato de que a expansão dos arranjos produtivos implica uma análise mais abrangente dos conceitos de desempenho e competitividade, em função do maior número de organizações envolvidas, das variadas relações de causa-e-efeito presentes e de suas diferentes características técnicas, econômicas, regionais, temporais e sociais.

Por outro lado, a construção de um sistema de avaliação sistêmica do desempenho competitivo para arranjos produtivos é possível e sua formulação teórica não constitui uma dificuldade tão grande quanto se poderia supor. Porém, tal sistema de indicadores de desempenho apresenta diferenças com relação à lógica tradicional de medição de desempenho de empresas individuais, sendo centrado em uma abordagem sistêmica do contexto. Com isso, busca-se maior esclarecimento sobre as relações entre as partes envolvidas, permitindo auxílio na definição de ações de melhoria de desempenho do coletivo. Este foco direcionado ao individual e ao coletivo simultaneamente, constitui o ambiente de análise que se convencionou denominar como mesoanalítico.

A proposta de modelo de avaliação sistêmica do desempenho competitivo de arranjos produtivos contida no presente trabalho não pode ser interpretada como conclusiva ou como tendo esgotado o tema em análise. Deve ser vista, isso sim, como um início de discussão relativamente a um tema que oferece diversos desdobramentos.

Apesar de estar em fase inicial de implantação, o modelo de avaliação sistêmica do desempenho competitivo já começa a apresentar os primeiros resultados práticos para as empresas envolvidas e para a entidade gestora do mesmo (entidade de classe). Porém, a comprovação de sua real eficácia só poderá ser obtida quando o mesmo estiver totalmente implantado e com uma base de dados que permita estabelecer conclusões abrangentes e coerentes.

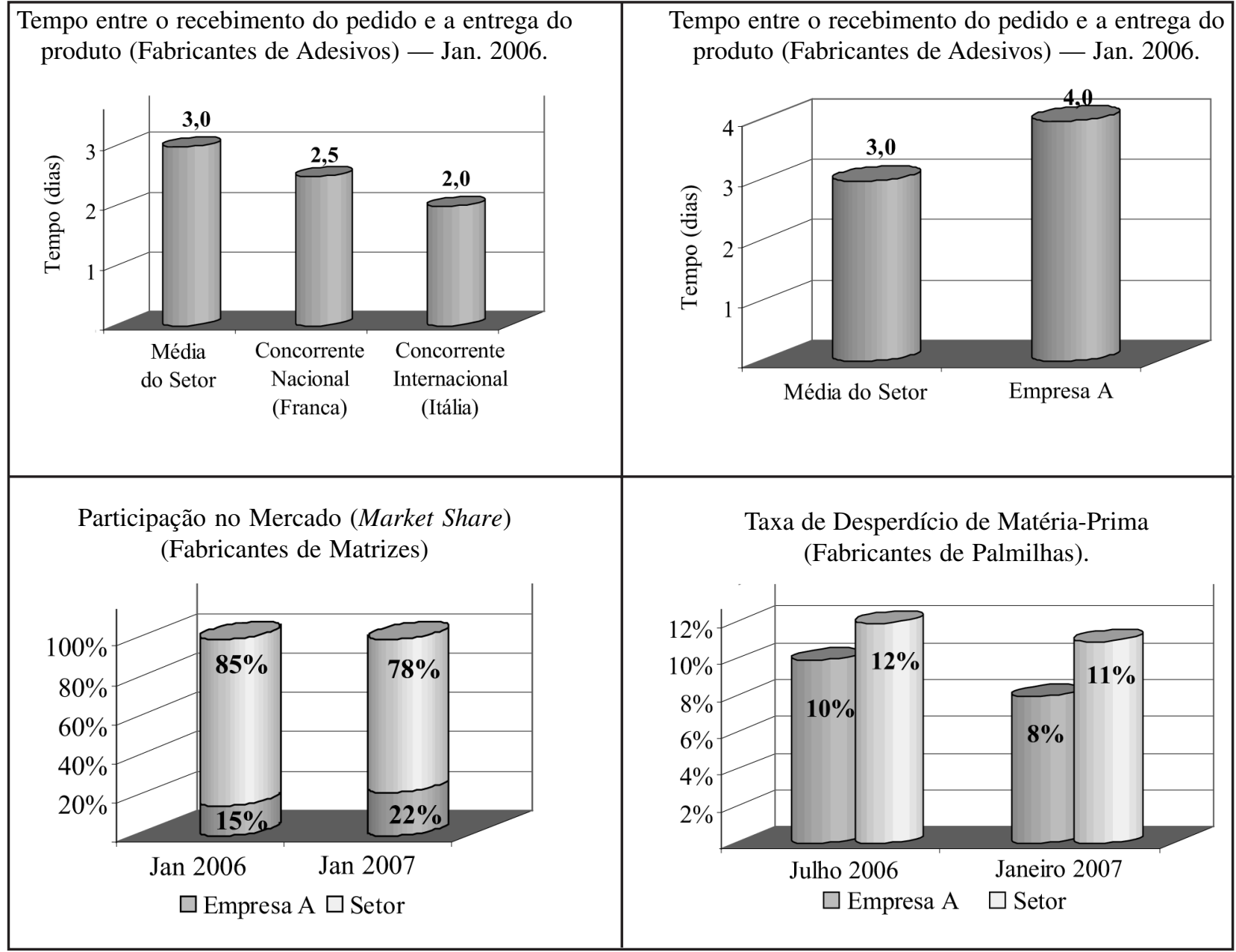

Figura 4 - Exemplos de resultados gerados pelo modelo de avaliação sistêmica do desempenho competitivo 


\section{Referências}

AMATO NETO, J. Redes de Cooperação Produtiva e Clusters Regionais. Fundação Vanzolini, São Paulo: Atlas, SP, 2000.

ASSINTECAL. Quantificação da produção da indústria calçadista. Associação Brasileira de indústrias de componentes para couro e calçados, Novo Hamburgo, 2006. Disponível em <http://www..assintecal.com.br> Acesso em 12 jan. 2008.

BATAlHA, M. O. Gestão Agroindustrial. São Paulo: Atlas, SP, 1997.

BEAMON, B. M. Measuring Supply Chain Performance. International Journal of Operations \& Production Management. V. 19, n. 3, p. 275-292, 1999.

CASAROTTO FILHO, N.; PIRES, L. H.. Redes de Pequenas e Médias Empresas e Desenvolvimento Local. Editora Atlas S.A., São Paulo, SP, 1998.

CASTRO, A. M. G. Análise da Competitividade de Cadeias Produtivas. Pesquisa da Embrapa, 2003. Disponível em <http://www.suframa.gov.br/download/publicacoes/ accp.pdf> Acesso em: 13 out. 2007.

CHORINCAS, J.; MARQUES, I.; RIBEIRO, J. F. Clusters e Políticas de Inovação: Conceitos, Experiências Européias e Perspectivas de Aplicação a Portugal. Disponível em: <www.dpp.pt> Acesso em: 10 jan. 2007.

CHRISTOPHER, M. Logística e Gerenciamento da Cadeia de Suprimentos. São Paulo: Editora Pioneira, 1997.

COUTINHO, L.; FERRAZ, J. C. Estudo da Competitividade da Indústria Brasileira. São Paulo, Campinas, Ed. Papirus, $3^{\text {a }}$ ed., 1995.

DORNIER, P.; ERNST, R.; FENDER, M.; KOUVELIS, P. Logística e Operações Globais: Texto e Casos. São Paulo: Atlas, 2000.

ESSER, K.; HILLEBRAND, W.; MESSNER, D.; MEYERSTAMER, J. Systemic Competitiveness: New Governance Patterns for Industrial Development. GDI Book Series, no. 7, London (United Kingdom), 172 p, 1996.

FENSTERSEIFER, J. E.; GOMES, J. A. Análise da Cadeia Produtiva do Calçado de Couro. In: FENSTERSEIFER, J. E. (org.). O Complexo Calçadista em Perspectiva: Tecnologia e Competitividade. Porto Alegre: Ortiz, 1995.
FERRAZ, J. C.; KUPFER, D.; HAGUENAUER, L. Made in Brazil, Desafios Competitivos para Indústria. Rio de Janeiro: Campus, 1996.

HANSEN, P.B.; BIASOLI, P. K.; CORTEZIA, S.; RITTER, F. Análise Preliminar da Cadeia Coureiro-Calçadista do RS. In: XXIII ENCONTRONACIONALDEENGENHARIA DE PRODUÇÃO, Ouro Preto, MG. Anais ..., Ouro Preto, MG, Brasil, 22-24 out. 2003.

HANSEN, P. B. Um Modelo de Medição de Desempenho Competitivo de Cadeias Produtivas. Tese de Doutorado. Universidade Federal do Rio Grande do Sul (UFRGS), Escola de Engenharia, Programa de Pós-Graduação em Engenharia de Produção (PPGEP). Porto Alegre, RS, Brasil, 2004.

HOLMBERG, S. A Systems Perspective on Supply Chain Measurements. International Journal of Physical Distribution \& Logistics Management. Vol. 30, No.10, p. 847-869, 2000.

KAPLINSKY, R.; MORRIS, M. A Handbook for Value Chain Research. London, IDRC, 2001. Disponível em: $<$ http://asiandrivers.open.ac.uk/documents/Value_chain_Handbook_RKMM_Nov_2001.pdf > Acesso em: 03 set. 2008.

KLIEMANN, F. J. Contribution Méthodologique a la Compréhension de la Dynamique des Filières: Analyse Strategique da la Filière Bois de Santa Catarina (Brésil). Tese de Doutorado. Institut National Polytechnique de Lorraine, France, 1985.

KLIEMANN, F. J.; HANSEN, P.B. Avaliação de Desempenho de Cadeias Produtivas: o Novo Desafio para a Competitividade Sistêmica. In: XXIII ENCONTRO NACIONAL DE ENGENHARIA DE PRODUÇÃO, Ouro Preto, MG. Anais ... Ouro Preto, MG, Brasil, 22-24 out. 2003.

LAMBERT, D.M. Supply Chain Management: What does it Involve? Supply Chain \& Logistics Journal, Fall 2001, Vol. 4, Issue 4, Canadian Association of Supply Chain \& Logistics Management, Canada, 2001.

LAMBERT, D.M.; POHLEN, T. L. Supply Chain Metrics. The International Journal of Logistics Management. Volume 2, N 1, p. 1-19, 2001.

MALHOTRA, N. K. Pesquisa de Marketing: uma orientação aplicada. $3^{\text {a }}$ ed. Porto Alegre: Bookman, 2001.

PEDROSO, E. A.; HANSEN, P. Clusters, Filière, Supply Chain, Redes Flexíveis: uma análise comparativa. Revista Análise, v.12, n.2, p. 7-19, 2001. 
PECK H.; JUTTNER, U. Strategy and relationships: Defining the interface in supply chain contexts, International Journal of Logistics Management, v.11, n.2, p. 33, 2000.

PIRES, M. S. Construção de Modelo Endógeno, Sistêmico e Distintivo de Desenvolvimento Regional e a sua Validação através da elaboração e da aplicação da Metodologia ao Caso do Mercoeste. Tese de Doutorado. Universidade Federal de Santa Catarina (UFSC), Programa de Pós-Graduação em Engenharia de Produção e Sistemas (PPGEPS), Florianópolis, SC, Brasil, 2001.

PORTER, M. E. Estratégia competitiva: técnicas para análise de indústrias e da concorrência. Rio de Janeiro: Campus, 1997.

PORTER, M. E. Clusters e Competitividade. HSM Management 15, Ano 3, n.15, jul. - ago., 1999.

RAIKES, P.; JENSEN, M. F.; PONTE, S. Global Commodity Chain Analysis and the French Filière
Approach, CDR (Center for Development Research), Copenhagen, Feb., 2000.

RUAS, R. O Conceito de Cluster e as Relações Interfirmas no Complexo Calçadista do Rio Grande do Sul. In: FENSTERSEIFER, J. E. (org.). O Complexo Calçadista em Perspectiva: Tecnologia e Competitividade. Porto Alegre: Ortiz, 1995.

VERSCHOORE, J. R. S. Redes de cooperação: uma nova organização de pequenas e médias empresas no Rio Grande do Sul. Ed. Fundação Economia e Estatística (FEE), Porto Alegre, RS, 2004.

WOOD, J. R., T:;ZUFFO, P. K. Supply Chain Management. RAE - Revista de Administração de Empresas, SP, V.38, N.3, p. 55-63. Jul./Set.1998.

YIN, R. K. Estudo de Caso: Planejamento e Métodos. $3^{\mathrm{a}}$ ed. Porto Alegre: Bookman, 2005. 